\title{
SOME QUANTITATIVE ASPECTS OF FEEDING IN SABELLID AND SERPULID FAN WORMS
}

\author{
By R. Phillips Dales \\ Bedford College, University of London
}

\section{INTRODUCTION}

It is apparent, from Jørgensen's recent review (1955) of quantitative aspects of filter feeding in invertebrates, that virtually nothing is known of the rate of filtering in polychaete suspension feeders, of which the sabellid and serpulid fan worms are perhaps the most important.

There seems to be little variation in the filter-feeding mechanism in different sabellid and serpulid polychaetes. The most detailed account of the feeding mechanism of these worms is that of Sabella published by Nicol (1930) with a résumé of earlier work on sabellids and serpulids. Some information on feeding and the anatomy of the crown in other genera may be found in the works of Soulier, I891 (Serpula, Hydroides, Protula, Branchiomma, Spirographis and Myxicola), Johansson, 1927 (Serpula and Pomatoceros) and Thomas, 1940 (Pomatoceros). That the crown arises as a paired structure from the prostomium was shown by Wilson (1936) in Branchiomma. In adults, the crown may retain a clearly divided form, as in many serpulids such as Pomatoceros, or form an almost continuous single cone as in Myxicola or Salmacina. It is not, however, the purpose of the present paper to describe these variations in morphology, but to present some quantitative data on the filtering process. The species investigated were those which could be obtained in sufficient quantity at Plymouth. The results of experiments on the sabellids, Myxicola infundibulum (Rénier) and Sabella pavonina Savigny, and on the serpulids, Pomatoceros triqueter (L.), Hydroides norvegica (Gunnerus), Spirorbis borealis Daudin, and Salmacina dysteri (Huxley) are presented here.

This work was done during the summer of 1956 at Plymouth, and I am grateful to the Director and Staff of the Laboratory for all the various facilities that made the work possible. I wish to thank especially Dr Dorothy Ballantine for supplying the algal cultures used, Mr R. F. H. Freeman, of Queen Mary College, for kindly lending me his absorptiometer, and Prof. G.P. Wells, F.R.S., for helpful criticism of the typescript of this paper, and discussion of the results. 


\section{METHODS}

The total volume of water strained, not the actual quantity of particles ingested, has been measured. Suspensions of 'Aquadag', a colloidal graphite suspension in water supplied by Acheson Colloids Ltd., London, was used. The method depends on the assumption that all the particles in the water filtered are removed from suspension, and those remaining are evenly distributed. The removal of particles from a closed system is exponential and as the filtering rate in fan worms was found not to vary with density, the volume and initial density of suspension could be adjusted to any convenient value. Both Jørgensen (1949), working with Mytilus, and Ballantine \& Morton (1956), working with another lamellibranch, Lasaea, have found graphite suspensions to give variable results. Nevertheless, all the worms investigated fed and behaved normally in 'Aquadag' suspensions, and the values for filtering rates obtained here were consistent for each species. The suspensions were made up in the following way. A knife-point of the graphite paste was shaken vigorously in a test-tube with distilled water for $\mathrm{I}-2 \mathrm{~min}$, and then poured into a small beaker. After $5 \mathrm{~min}$ the resulting suspension was carefully decanted into a bottle, made up to $50 \mathrm{ml}$. with distilled water and allowed to stand a further $5 \mathrm{~min}$. Such freshly made-up suspensions were used for each experiment and were found to give even suspensions consisting of particles almost entirely $\mathrm{I}-2 \mu$ in size, with a few larger particles up to $4-5 \mu$. In distilled water such dilutions are stable for at least some days. For the experiments, $\mathrm{I}-2 \mathrm{ml}$. of this stock suspension was added to about $250 \mathrm{ml}$. of sea water. After $4 \mathrm{~h}$ all the particles were less than Io $\mu$ and most $\mathrm{I}-2 \mu$ across. After $12 \mathrm{~h}$, aggregates up to $50-60 \mu$ had appeared; $18 \mathrm{~h}$ afterwards, Ioo $\mu$ aggregates had formed, and after $24 \mathrm{~h}$ the aggregates rapidly sedimented. The optical density decreases during this aggregation process, but not materially during the first $4 \mathrm{~h}$ after preparing the sea-water suspension. The density of the suspension and the number of animals used in each experiment was therefore adjusted to give an easily measurable value in $2-3 \mathrm{~h}$. The rate of filtering was calculated from the formula used by Jørgensen (I943) from measurements of the decrease in optical density of the suspension by means of an absorptiometer. Jørgensen (1949) found a change in feeding rate during the experiments using colloidal graphite with Mytilus. This may have been due to the suspensions being initially uneven, rather than to more rapid aggregation of small particles. Only by following the shaking and decanting process described here was it found possible to obtain even and stable suspensions. In some test experiments with Myxicola, estimation of filtering rate using suspensions in sea water, 12 and $18 \mathrm{~h}$ old, did not give values significantly different from those obtained with freshly made suspensions. While much of the graphite was ingested by the worms in all experiments, some was rejected, probably owing to the rather dense sus- 
pensions used. As all the particles caught on the pinnules become entangled in mucus, however, the fall in optical density of the suspension gives a measure of the volume strained through the crown. Probably under natural conditions, where the density of small particles in suspension is much less, the majority of suitable particles would be ingested, so that the filtering rate becomes equivalent to the feeding rate.

Animals were acclimatized for some days to the experimental vessels kept under circulation before measurement of filtering rate. Care was taken to see that the animals were filtering and behaving normally before each experiment. Most species, especially Sabella, were found to become much less sensitive to shock if the vessels containing the animals were handled repeatedly for a day or so before the experiment. This was done so that the supernatant water could be sampled for measurement of optical density without causing retraction of the worm and interruption of feeding. Momentary, and apparently spontaneous, retractions take place, but the recovery and resumption of filtering is more prompt than after a shock reaction. Hydroides was found the most sensitive to experimental conditions. The Sabella (in their own tubes), were arranged individually, in small specimen tubes cemented to the bottom of the vessel, so that the crowns could be expanded and twirled without obstruction. Myxicola was allowed to secrete new tubes in the bottom of the vessel before being used in an experiment. Vessels with a capacity of $750 \mathrm{ml}$. were used for these large sabellids, with $\mathrm{I}-3$ worms in each. For the experiments on Pomatoceros, animals were selected with their tubes cemented to pebbles of convenient size, and these scraped clean of other filter-feeding animals before being acclimatized to vessels of $250-300 \mathrm{ml}$. capacity. Hydroides, growing on Pecten and Buccinum shells, were placed in $100 \mathrm{ml}$. vessels; pieces of Salmacina colony, and Spirorbis growing on Fucus, were placed in $10 \mathrm{ml}$. vessels for measurement of their filtering rates.

The worms used in the experiments were dried on filter paper and weighed; the larger species individually. Spirorbis and Salmacina were weighed in batches. Ten worms were placed on a cover-slip, the crowns dissected off, and surplus moisture drained off with filter paper; the whole process being performed under a binocular microscope. After weighing, the crowns were removed, and the cover-slip weighed again; the difference was taken as the weight of the crowns. Weighing was performed on an aperiodic microchemical balance with a sensitivity of $0.0 \mathrm{I} \mathrm{mg}$. In serpulids, the operculum and its stalk were dissected off, and, while included in the total body weight, are excluded from the weight of the crown. The extreme values for the weights of Salmacina and Spirorbis (Table I, column 4) represent the means of ten of the largest and ten of the smallest selected from those used in the experiments. 
TABLE 1. RESULTS OF EXPERIMENTS ON FILTERING RATES USING COLLOIDAL GRAPHITE SUSPENSIONS (The figures in parentheses represent the number of animals or experiments from which each calculation is derived)

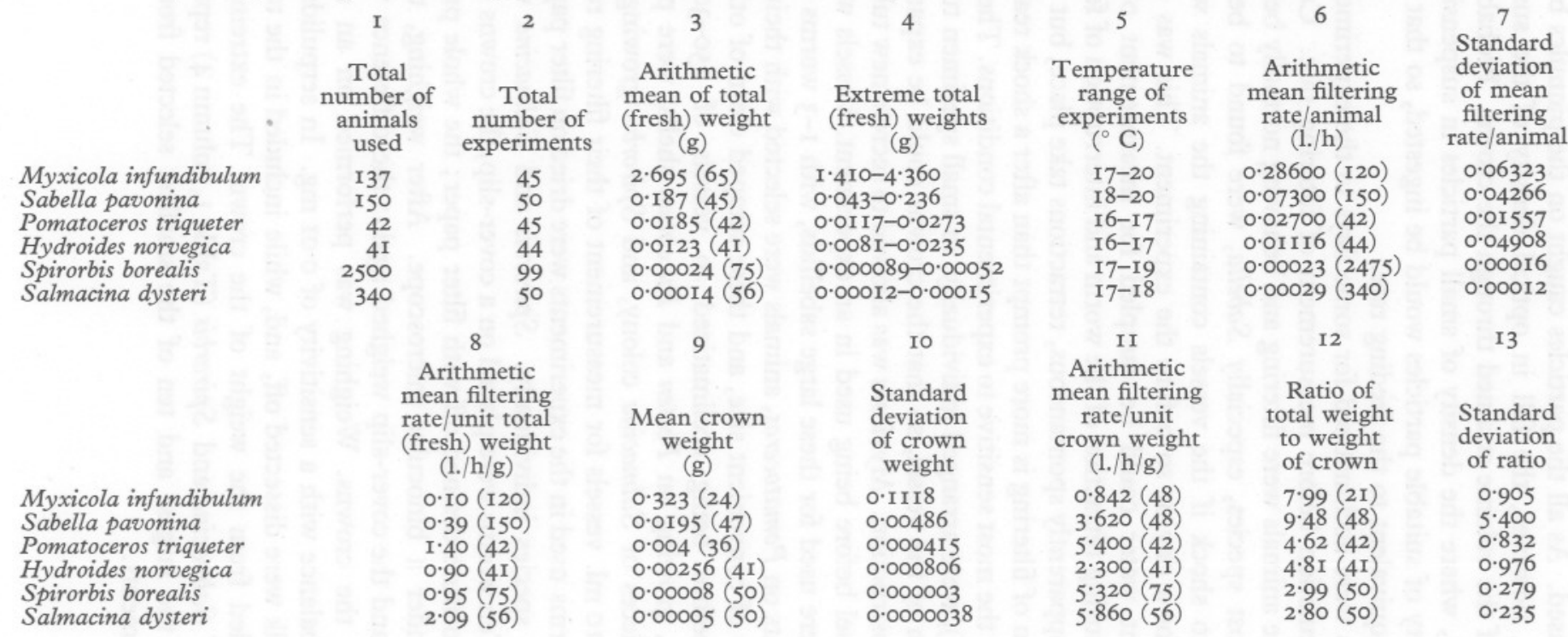




\section{DISCUSSION OF THE RESULTS}

The results of all the experiments using colloidal graphite suspensions are summarized in Table $\mathrm{I}$. The detailed results need not be given here; measurements and calculations of general interest are included in the table, and the consistency of the values obtained may be judged from the standard deviations given, bearing in mind the random selection of the animals and their size range. About fifty experiments were performed on each species.

It is not surprising that the largest species, Myxicola infundibulum, should have the highest individual filtering rate $(286 \mathrm{ml} . / \mathrm{h})$, which is over 1000 times that of Salmacina and Spirorbis $(0.23-0.29 \mathrm{ml}$./h). On the other hand, the size range within the group is very great; the weight of Myxicola is over 25,000 times that of Salmacina. Thus the largest species have lower filtering rates per unit of weight than the smallest. This is in accordance with the general dictum that larger animals have lower metabolic rates than smaller ones within a phylogenetic series. The respiration rates of the smaller serpulids have not been measured, but Wells (1952) found the respiration rate of Myxicola to be $0.035 \mathrm{ml} . \mathrm{O}_{2} / \mathrm{g}$ fresh weight $/ \mathrm{h}$, and Sabella about $0.05 \mathrm{ml} . \mathrm{O}_{2} / \mathrm{g} / \mathrm{h}$, a similar value for Sabella having been found also by Ewer \& Fox (1940). It is of interest to note also that, as far as is known, the larger species with lower filtering rates have a longer life span than the smaller. Spirorbis borealis lives for a few months only, Pomatoceros for at least two or three years (Robertson \& Pantin, 1938), and a single Sabella has been recorded as living in the Plymouth Aquarium for at least ten years (Wilson, 1949).

If the filtering rate is expressed as a function of the crown weight alone, it is found that the rates are not significantly different in any of the species studied. The higher filtering rates per unit total weight in the smaller species are therefore not attained by crowns which for some structural reason are more efficient-that is, capable of straining a larger quantity of water per unit weight and time-than those of larger species, but rather of having relatively larger crowns. In Spirorbis, the crown represents a third of the total weight, in Hydroides about a fifth, in Sabella only a ninth. Conversely, the greater apparent complexity of the crown in Myxicola must be related to other factors. While both Myxicola and Sabella are found at the mouths of estuaries in mud banks, Sabella builds a tube projecting well above the surface, so that when the crown is expanded it is held away from the bottom. The slimy tubes of Myxicola are completely buried, so that the expanded crown only just projects from the surface. The inter-filamentary membranes probably prevent the crown from becoming clogged, the current bearing the finer suspended particles on which the worms feed entering from the rim. As Wells (1952) noticed, the pinnules are somewhat rotated so that the ventro-lateral cilia have a stronger longitudinal, as opposed to transverse, component with 
reference to the axis of the filament. The high standard deviation of the ratio of crown to total body weight (Table I, column I3) in Sabella is due to some of the animals having partially regenerated crowns.

With the larger species it was not found practicable to measure the filtering rate with algal cultures owing to the very large volume which would be required. A few experiments using Phaeodactylum tricornutum Bohlin with Myxicola, and a number using cultures of Phaeodactylum, Isochrysis galbana Parke, and Chromulina pusilla Butcher, were made with Spirorbis. These three species of algae were selected, not only because of their availability at the Plymouth Laboratory, but because of their size differences: Phaeodactylum cells are $20-40 \mu$; Isochrysis, 5-6 $\mu$; Chromulina, I-2 $\mu$ in length. All the fan worms avoided dense suspensions of Phaeodactylum and Isochrysis, and even when much diluted the filtering rates were very small compared with those obtained with colloidal graphite. Myxicola and Spirorbis both removed Phaeodactylum from suspension at less than a tenth of the rate recorded with colloidal graphite. The other fan worms would not keep their crowns expanded in dense suspensions of these algae. This is certainly not merely a matter of size. Myxicola in I8 h old 'Aquadag' suspensions filtered at the same rate as in freshly made suspensions in which the majority of the particles were less than $2 \mu$, and which had a greater density than the Phaeodactylum suspensions used. Chromulina are closely similar to such fresh graphite particles in size, but dense suspensions of this alga produced repeated retractions of the crown in Spirorbis. The Spirorbis would remain with the crown expanded in more dilute cultures, but the filtering rate was negligible. One can only conclude that these algae can escape from the pinnules which are thus only capable of filtering inert particles of detritus from suspension. This is perhaps one explanation of the abundance of fan worms at the mouths of estuaries where there is much fine detritus in suspension.

During the present work a few experiments were made on Chaetopterus, using 'Aquadag' suspensions. Using seventeen different animals in their own tubes in groups of $\mathrm{I}-3$, allowing $\mathrm{I} \cdot 51$. of suspension for each group, and measuring the filtering rate over a $2 \mathrm{~h}$ period, it was found that at $16^{\circ} \mathrm{C}$ the mean filtering rate was $0.31 . / \mathrm{h} /$ animal (standard deviation $0.1831 . / \mathrm{h}$ ). The mean fresh weight of these animals was $6.0 \mathrm{~g}$, giving a value of $0.051 . / \mathrm{h} / \mathrm{g}$. Jørgensen (1955) calculated the filtering rate as 0.961 . $/ \mathrm{h}$ from data given by Wells (Wells \& Dales, I95I), but this was based on a calculation of the flow through the tube of one worm on a single occasion. The highest value obtained here over the $2 \mathrm{~h}$ period was $0.751 . / \mathrm{h}$, in a vessel containing a single animal. It is known from the work of MacGinitie (I939) and Wells (Wells \& Dales, I95I) that Chaetopterus may both irrigate the burrow without feeding and feed without secreting a complete mucus bag such as might be expected to retain all the graphite particles in the water strained. It is also known that such activities are discontinuous. The value for the 'filtering rate' given here 
may, therefore, bear little relation either to the feeding rate or the total volume of water passed, and is not comparable with the values for fan worms which filtered more or less continuously during the course of an experiment. It is impossible to observe the activity of the animals in their own tubes as these are opaque.

The values obtained for the fan worms (Table I) are all low compared with known values for other invertebrates. For example, from the information given by Jørgensen (1955), derived from various sources, Ostrea virginica filters at the rate of about $0.51 . / \mathrm{h} / \mathrm{g}$, Mytilus edulis at $\mathrm{r} \cdot 61 . / \mathrm{h} / \mathrm{g}$ and Ciona intestinalis at $0.231 . / \mathrm{h} / \mathrm{g}$, at comparable temperatures. Ciona has much the same fresh weight as Myxicola, which strains at less than half this rate (O.I 1./h/g). Clearly the fan worms are less efficient than other suspensionfeeding invertebrates, both in the volume of water they are capable of straining, and in the kind of particles which can be retained. While some sorting according to size occurs in Sabella (Nicol, 1930) and in other fan worms, this is crude compared with sorting mechanisms in some other suspension-feeding invertebrates.

\section{SUMMARY}

The rate of filtering has been examined in a series of sabellids and serpulids of widely different size, using suspensions of colloidal graphite and algal cultures. The filtering rates have been expressed as individual rates, as the volume strained per unit fresh weight, and per unit weight of the crown. It may be concluded that the smaller fan worms filter at a relatively higher rate than the larger. This is achieved partly by the relatively larger crown. Free swimming algae escape through the crown; only inert particles down to I-2 $\mu$ are retained, implying that fan worms depend on suspended detritus alone. The filtering rates are briefly compared with those of Chaetopterus and some other filter-feeding invertebrates.

\section{REFERENCES}

Ballantine, D. \& Morton, J. E., I956. Filtering, feeding, and digestion in the lamellibranch Lasaea rubra. F. mar. biol. Ass. U.K., Vol. 35, pp. 24I-74.

EwER, R. F. \& Fox, H. M., I940. On the function of chlorocruorin. Proc. roy. Soc. B, Vol. 129, pp. 137-53.

Johansson, K. E., I927. Beiträge zur Kenntnis der Polychaeten-Familien Hermellidae, Sabellidae und Serpulidae. Zool. Bidr. Uppsala, Bd. II, pp. I-I83.

JørGENSEN, C. B., 1943. On the water transport through the gills of bivalves. Acta physiol. scand., Vol. 5, pp. 297-304.

— 1949. The rate of feeding by Mytilus in different kinds of suspension. F. mar. biol. Ass. U.K., Vol. 28, pp. 333-44.

- 1955. Quantitative aspects of filter feeding in invertebrates. Biol. Rev., Vol. 30, pp. $39 \mathrm{I}-454$.

MacGinitie, G. E., 1939. The method of feeding of Chaetopterus. Biol. Bull., Woods Hole, Vol. 77, pp. II 5-18. 
Nicol, E. A. T., I930. The feeding mechanism, formation of the tube, and physiology of digestion in Sabella pavonina. Trans. roy. Soc. Edinb., Vol. 56, pp. 537-98.

Robertson, J. D. \& Pantin, C. F. A., 1938. Tube formation in Pomatoceros triqueter (L.). Nature, Lond., Vol. I4I, pp. 648-9.

SoulIER, A., I89I. Études sur quelques points de l'anatomie des Annélides tubicoles de la région de Cette. Trav. Inst. Zool. Univ. Montpellier, T. 2, pp. I-3Io.

Thomas, J. G., 1940. Pomatoceros, Sabella and Amphitrite. L.M.B.C. Memoirs, No. 33,88 pp. Liverpool: University Press.

WELLS, G. P., 1952. The respiratory significance of the crown in the polychaete worms Sabella and Myxicola. Proc. roy. Soc. B, Vol. 140, pp. 70-82.

Wells, G. P. \& Dales, R. P., I95I. Spontaneous activity patterns in animal behaviour: the irrigation of the burrow in the polychaetes Chaetopterus variopedatus Renier and Nereis diversicolor O. F. Müller. F. mar. biol. Ass. U.K., Vol. 29, pp. 66I-80.

Wilson, D. P., 1936. The development of the sabellid Branchiomma vesciculosum. Quart. F. micr. Sci., Vol. 78, pp. 543-603.

- 1949. Notes from the Plymouth Aquarium. F. mar. biol. Ass. U.K., Vol. 28, pp. $345-5$ I. 